\title{
Oxidation and silanization of MWCNTs for MWCNT/vinyl ester composites
}

\author{
F. Avilés ${ }^{*}$, J. V. Cauich-Rodríguez, J. A. Rodríguez-González, A. May-Pat \\ Centro de Investigación Científica de Yucatán, A.C., Unidad de Materiales Calle 43 \# 130, Col. Chuburná de Hidalgo, \\ 97200, Mérida, Yucatán, México
}

Received 27 December 2010; accepted in revised form 1 March 2011

\begin{abstract}
Chemical functionalization of multi-wall carbon nanotubes (MWCNTs) is conducted by means of acid oxidation, direct silanization of the as-received MWCNTs and a sequential treatment based on oxidation and silanization. Polymer composites made from the functionalized MWCNTs and a vinyl ester resin are fabricated and tested in compression. It is found that although silanization could be achieved without the assistance of a previous oxidative treatment, oxidizing the MWCNTs by $\mathrm{HNO}_{3} / \mathrm{H}_{2} \mathrm{O}_{2}$ prior to silanization yields significantly better attachment of the silane molecules to the CNT surface and hence, better mechanical performance of the resulting composite. The limited improvements in mechanical properties found are discussed in light of the reduction of the nanotube length after MWCNT oxidation and composite processing.
\end{abstract}

Keywords: nanocomposites, functionalization, silanization, oxidation, carbon nanotubes

\section{Introduction}

The potential of carbon nanotubes (CNTs) as reinforcing elements in composite materials is based not only on the extraordinary mechanical properties of CNTs, but also on their relatively high aspect ratio $(L / d)$ and surface area-to-volume ratio $(A / V)$ [1-3]. Structures with high $L / d$ are known to be more load-carrying efficient, while high $A / V$ means more surface area at the same volume (weight). For composite materials, this yields an increase of the surface area of the reinforcing phase, and thus an increase of the region where stress transfer between the nanotube and matrix occurs. Thus, good interfacial bonding is important to guarantee adequate functionality of the composite $[4,5]$. In spite of their great promises, several issues still hold the potential of carbon nanotubes as reinforcing agents for polymer composites, as stated in numerous studies [1, 2, $6,7]$. When such nanostructures are incorporated into a polymer matrix, the most important issues recognized are interfacial bonding with the matrix, adequate dispersion, and preservation of the CNT length [2, 6-11]. Given the dissimilar surface chemistry of CNTs and most polymer matrices, several attempts have been conducted to modify the surface of CNTs to improve their bonding to polymer matrices $[4,5,12-14]$. The general idea of these methods is to improve the CNT/polymer interfacial bonding by promoting chemical (covalent or noncovalent) interactions. In this regard, chemical functionalization (oxidation, amination, silanization, etc.) promotes the formation of functional groups at the nanotube surface, which may react with the functional groups of the organic polymer forming permanent bonds [4, 5, 15-17]. Among the most frequent functionalization techniques reported to improve mechanical properties of CNT-thermosetting polymer composites are oxidations $[5,15-18]$

\footnotetext{
${ }^{*}$ Corresponding author, e-mail: faviles@cicy.mx

(c) BME-PT
} 
and amine based treatments $[5,13,19,20]$, while CNT silanization has been less reported in the open literature [21-25]. Although silane treatments are quite common for micron-size fiber-reinforced polymers, such treatments have not been thoroughly examined for CNTs. Pioneering efforts on CNT silanization for epoxy nanocomposites have been conducted by the groups of Ma and coworkers $[22,25]$ and Kathi and Rhee and coworkers [23, 24, 26]. Ma et al. [25] reported a three-step procedure to functionalize multi-wall carbon nanotubes (MWCNTs) based on oxidation by UV light, reduction with $\mathrm{LiAlH}_{4}$ and finally nanotube silanization. The process presented by these authors successfully functionalized the surface of MWCNTs and improved the dispersion of the MWCNTs within an epoxy matrix and, consequently, the flexural properties of the composite. Recently, Kim et al. [26] conducted a functionalization procedure based on acid oxidation followed by silanization, and their results suggest slight improvements in the flexural properties of epoxy nanocomposites. To our knowledge, results for silanized CNT composites employing a vinyl ester thermosetting matrix (commonly used in resin infusion processes for composites manufacturing) have not been reported. Commercial CNTs commonly receive a proprietary purification treatment which frequently creates some functional groups on the CNT surface. The need of further oxidation previous to CNT silanization has also not being systematically addressed.

In this work, MWCNTs are chemically functionalized by three different methods: i) wet acid oxidation, ii) silanization of as-received nanotubes (without previous oxidation), iii) CNT silanization after acid and $\mathrm{H}_{2} \mathrm{O}_{2}$ oxidation. Elemental microanalysis and the presence of functional groups on the CNTs surface caused by oxidation and silanization are investigated by energy dispersive spectroscopy (EDX) and infrared spectroscopy (FT-IR), respectively. The functionalized MWCNTs are then employed to fabricate nanocomposites of vinyl ester resin, evaluating their compressive performance.

\section{Materials and methods}

\subsection{Materials}

CVD-grown MWCNT agglomerates were purchased from Bayer MaterialScience (Leverkusen, Germany) [27]. The nanotubes ('Baytubes $\mathrm{C} 150 \mathrm{P}^{\circledR}$ ') have an inner diameter of approximately $4 \mathrm{~nm}$, outer mean diameter of $13-16 \mathrm{~nm}$, and a typical length distribution between 1 and $4 \mu \mathrm{m}$. The as-purchased material has over $95 \%$ nanotube content with amorphous carbon and very small traces of metal catalyst as impurities. The resin employed was a Derakane 'Momentum 470-300 ${ }^{\circledR}$ ' epoxy vinyl ester resin from Ashland Composites (Covington, KY, USA) [28], which is typically used for resin infusion molding due to its low viscosity (styrene content $33 \mathrm{wt} \%$ ). The initiator was Methyl Ethyl Ketone Peroxide (Norox MEKP-925, Syrgis, Helena, AR, USA) and Cobalt Naphthenate (CoNap) was used as promoter, both at $0.5 \% \mathrm{w} / \mathrm{w}$ with respect to the weight of the vinyl ester resin. The silane coupling agent employed to functionalize the MWCNTs was 3-methacryloxypropyltrimethoxysilane (MPTMS), which is employed as a coupling agent for free radicals cured resins, such as vinyl esters. This silane has a methacrylate organo-reactive group and trimethoxy hydrolyzable groups, which matches the organofunctional group of the vinyl ester resin employed.

\subsection{Nanotube oxidation and silanization}

Chemical oxidation was carried out using a sequential treatment based on $3.0 \mathrm{M}$ nitric acid followed by hydrogen peroxide $(30 \% \mathrm{v} / \mathrm{v})$. For the oxidative treatment, $0.3 \mathrm{~g}$ of the agglomerated MWCNTs were first mixed with $70 \mathrm{ml}$ of $\mathrm{HNO}_{3}$ and mechanically stirred in a stirring plate for 15 minutes. The mixture was then sonicated in an ultrasonic bath for $2 \mathrm{~h}$, promoting CNT disentanglement within the acid solution. Then, the slurry was filtered, thoroughly washed with distilled water and the process repeated using $\mathrm{H}_{2} \mathrm{O}_{2}$. This mild oxidative process has been previously reported [29], and scanning electron micrographs did not show evidence of significant CNT damage.

Silanization was achieved by first dispersing $0.3 \mathrm{~g}$ of MWCNTs in ethanol (48 g) for $1 \mathrm{~h}$ using an ultrasonic bath. Simultaneously, 0.6 g of MPTMS were hydrolyzed by dissolution in $12 \mathrm{~g}$ of ethanol (J. T. Baker, analytic grade, $0.1 \% \mathrm{H}_{2} \mathrm{O}$, Mallinckrodt Baker, Inc. Phillipsburg, NJ, USA) using a magnetic stirrer for $1 \mathrm{~h}$ at room temperature $\left(28^{\circ} \mathrm{C}\right)$. Both solutions were then mixed in a sonicating bath for $1 \mathrm{~h}$ and mechanically stirred for $2 \mathrm{~h}$ at $60^{\circ} \mathrm{C}$. Ethanol was then fully evaporated inside a vacuum 


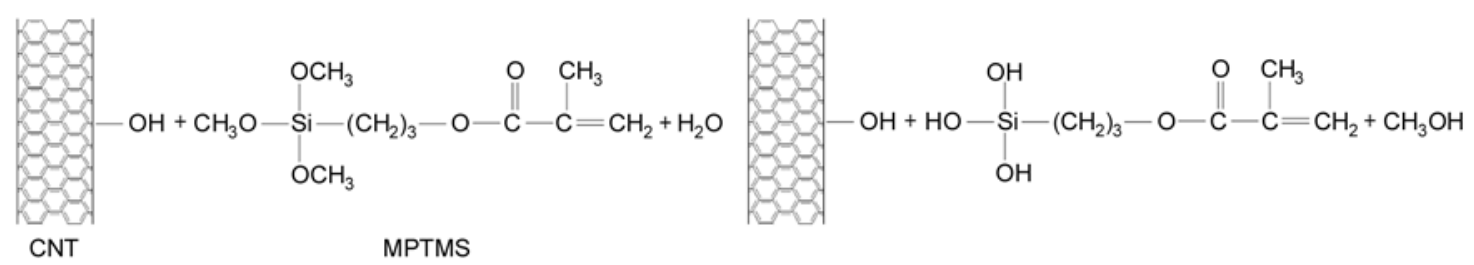

a)

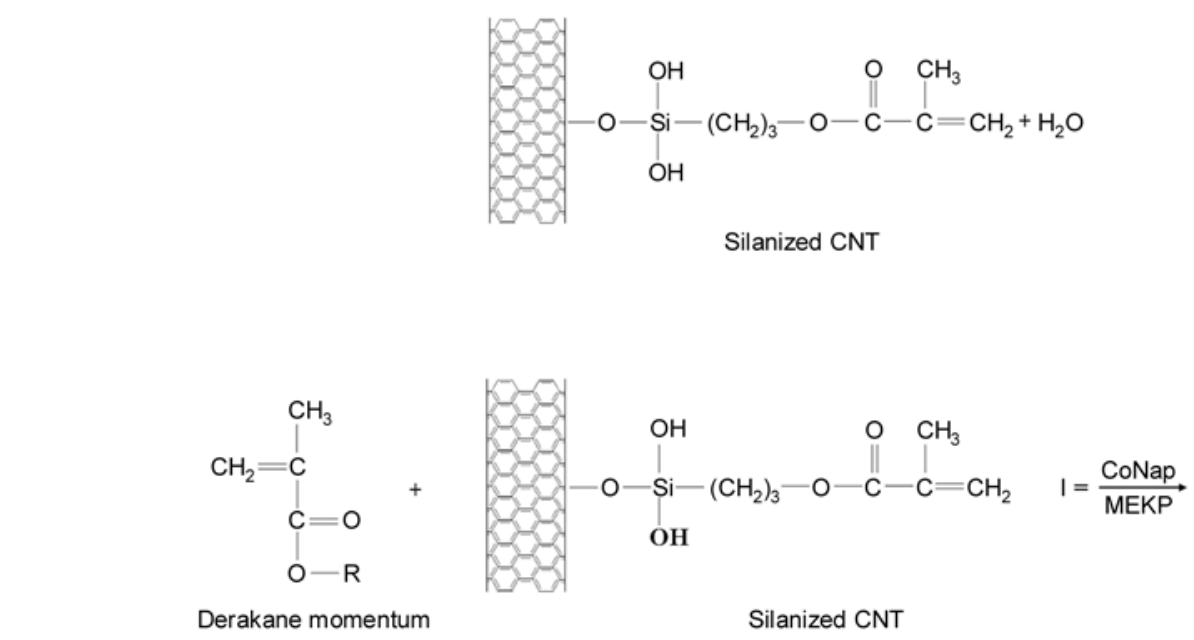

b)

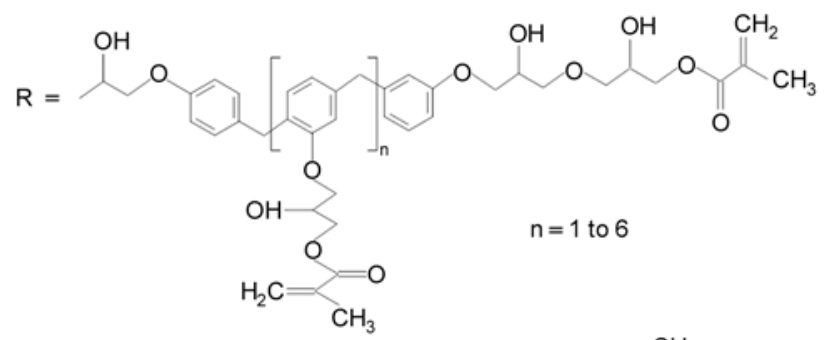

Figure 1. Schematic representation of CNT silanization and its bonding to the polymer matrix. a) CNT silanization with MPTMS, b) reaction of silanized CNT with the vinyl ester resin.

oven and MWCNTs were further dried at $150^{\circ} \mathrm{C}$ for $4 \mathrm{~h}$ to further improve condensation of silanol groups at the CNT surface. The silanized MWCNTs were intensively washed with ethanol, acetone and distilled water (sequentially) and dried in an oven at $150^{\circ} \mathrm{C}$. Identical processes were employed to silanize the as-received MWCNTs and MWCNTs that had been previously oxidized as described above. Figure 1a depicts the chemical reactions occurring during silanization. Briefly, the oxidized surface contains hydrophilic hydroxyl groups $(\mathrm{OH})$ that will serve as reaction sites. The silane coupling agent contains a trimethoxy group that after hydrolyisis will also form hydroxyl groups. The hydroxyl groups on the CNT and silane will condense in order to attach covalently a methacrylate group (hydrophobic) on the surface. The methacrylate group, also an ester, matches the chemical structure of the vinyl ester matrix. Thus, the silane coupling agent is expected to act as a bridge at the interface between the carbon nanotube and the vinyl ester matrix. 


\subsection{Preparation of nanocomposites}

Nanocomposites consisting of a vinyl ester resin loaded with $0.5 \% \mathrm{w} / \mathrm{w}$ MWCNTs were prepared using an ultrasonic-mechanical method to disperse the nanotubes within the resin. First, the desired amount of MWCNTs $(0.2 \mathrm{~g})$ was dispersed in acetone $(40 \mathrm{~g})$ for $2 \mathrm{~h}$ using an ultrasonic bath. The nanotubes/acetone solution was then mixed with the resin $(40 \mathrm{~g})$ and sonicated for $2 \mathrm{~h}$ in a cooled ultrasonic bath. The mixture MWCNTs/resin/acetone was then mechanically stirred in a hot plate until the acetone was evaporated. Since evaporation of styrene is also a possibility, the resin was initially weighted and gravimetric monitoring was conducted during the acetone evaporation process to maintain a constant amount of styrene in the resin, which was about $27 \mathrm{wt} \%$ for all specimens.

MWCNTs/resin mixtures were degassed under vacuum for approximately $1 \mathrm{~h}$, and then mixed with $0.5 \% \mathrm{w} / \mathrm{w}$ CoNap and MEKP before casting into silicon moulds. Following this procedure, nanocomposites were prepared using as-received (AR) MWCNTs, as well as MWCNTs that were oxidized only (Ox), silanized without previous treatment (Sil), and silanized after the oxidative treatment (Ox-Sil). For reference, blank specimens of vinyl ester resin (VER) were also prepared following the same procedure as for nanocomposites. The specimens were molded as per the standard, requiring only polishing after casting. The nomenclature employed for the treatments and materials is listed in Table 1.

The possible chemical reaction occurring between the silanized MWCNT and vinyl ester resin is described in Figure 1b. The methacrylate groups on the silanized MWCNT will undergo free radical polymerization (initiated by the redox system CoNap/MEKP) in the presence of vinyl groups leading to a crosslinked network.

Table 1. Nomenclature of treatments/materials employed in this work

\begin{tabular}{|l|c|}
\hline \multicolumn{1}{|c|}{ Material/treatment } & Identification \\
\hline Neat vinyl ester resin & VER \\
\hline As-received MWCNTs & AR \\
\hline Oxidized MWCNTs & Ox \\
\hline Silanized MWCNTs without previous oxidation & Sil \\
\hline Silanized MWCNTs after oxidation & Ox-Sil \\
\hline
\end{tabular}

\subsection{Experimental characterization}

The presence of silicon and new functional groups on the carbon nanotubes were assessed by microanalysis (EDX) and infrared spectroscopy (FT-IR). EDX/SEM analyses were carried out in a JEOL, JSM-6360-LV equipment coupled with an INCA Energy 200 detector (Oxford Instruments). For the EDX analysis, the MWCNT powder was affixed to a cooper support by means of a double-sided bonding copper tape. FT-IR spectra were obtained using $\mathrm{KBr}$ discs containing a very small amount of MWCNTs. The MWCNTs were first dispersed in acetone and a small drop added to the $\mathrm{KBr}$ powder. The KBr-MWCNTs powder was then diluted with additional $\mathrm{KBr}$ and analyzed several times, until a clear spectrum was obtained. The FT-IR analysis was conducted with a Nicolet-Protege 460 in the spectral range from 4000 to $600 \mathrm{~cm}^{-1}$. Microanalysis and FT-IR spectra were obtained on each sample and the results presented correspond to the representative ones. An FEI-TITAN microscope $\left(C_{\mathrm{s}}=\right.$ $1.25 \mathrm{~mm}$ ) operated at $300 \mathrm{kV}$ and registered near Scherzer focus was employed for transmission electron microscopy (TEM). TEM samples of treated and as-received MWCNTs were prepared on lacey carbon grids using dispersion in an ultrasonic bath for 30 minutes.

Axial compression of the composites and neat resin specimens was conducted in a Shimadzu AGI-100 universal testing machine, following ASTM standard D695 [30]. Compression specimens were prismatic with a length of $25.4 \mathrm{~mm}$ and square crosssectional area of $12.7 \times 12.7 \mathrm{~mm}^{2}$. Cross head speed was $1 \mathrm{~mm} / \mathrm{min}$ and eight replicates were used for each treatment.

\section{Results and discussion}

\subsection{Functionalization of MWCNTs}

EDX and FT-IR analyses were conducted in order to investigate the generation of oxygen containing species and attachment of silane molecules to MWCNTs. Table 2 presents the chemical composition of as-received (AR) MWCNTs, and nanotubes functionalized by oxidation only $(\mathrm{Ox})$, silanization of the AR nanotubes (Sil), and silanization of the Ox nanotubes (Ox-Sil). It is observed that the AR nanotubes are mainly composed of carbon and oxy- 
Table 2. EDX chemical composition (atomic \%) of asreceived and functionalized MWCNTs

\begin{tabular}{|l|c|c|c|c|}
\hline \multirow{2}{*}{ Element } & \multicolumn{4}{|c|}{ Treatment } \\
\cline { 2 - 5 } & AR & Ox & Sil & Ox-Sil \\
\hline $\mathrm{C}$ & 95.57 & 93.24 & 95.50 & 94.39 \\
\hline $\mathrm{O}$ & 3.60 & 6.67 & 4.02 & 4.56 \\
\hline $\mathrm{Si}$ & - & - & 0.06 & 0.89 \\
\hline $\mathrm{Mg}$ & 0.21 & - & 0.10 & - \\
\hline $\mathrm{Al}$ & 0.21 & 0.04 & 0.12 & 0.03 \\
\hline $\mathrm{Mn}$ & 0.21 & - & 0.06 & - \\
\hline $\mathrm{Co}$ & 0.21 & 0.02 & 0.06 & - \\
\hline
\end{tabular}

- Not detected

gen, with a few metal impurities such as $\mathrm{Mg}, \mathrm{Al}$, $\mathrm{Mn}$, and Co likely originated during the production or purification process. After oxidation with nitric acid and hydrogen peroxide (Ox), the great majority of the metal impurities are removed given the recognized action of $\mathrm{HNO}_{3}$ as a purifying agent $[15,16,18]$. For this treatment, additional oxygen containing groups are introduced on the CNT surface, as indicated by the increase in oxygen content shown in Table 2. For the CNTs that are directly silanized from the AR material (Sil), the metal impurities contained in the AR material are not eliminated since the $\mathrm{HNO}_{3}$ treatment was not conducted on these samples. The amount of oxygen in Sil samples is similar to that of the AR material and only a small amount of $\mathrm{Si}(0.06$ atomic\%) appears in the EDX quantification, suggesting that the covalent attachment of silane molecules may be marginal for this sample. However, when the CNTs are oxidized first and then silanized (Ox-Sil), the metal impurities almost disappear (because of the $\mathrm{HNO}_{3}$ treatment) and a significant amount of $\mathrm{Si}$ (0.89 atomic\%) is observed from the quantitative analysis. Therefore, these results suggest that silane molecules are better bonded to the CNT surface when an oxidative treatment is conducted before silanization. It is also noted that the oxygen content decreases for the Ox-Sil samples with respect to the Ox ones, which may be somewhat controversial. Although the MPTMS has five oxygen atoms (which should increase the oxygen content), the condensation of the silane with surface $\mathrm{OH}$ groups could cover the oxygen groups at the CNT surface, hindering their detection by EDX.

Figure 2 shows FT-IR spectra of the AR and functionalized CNTs examined in this work. For the asreceived MWCNTs (Figure 2a) the IR spectrum shows important absorption bands at $3436 \mathrm{~cm}^{-1}$ (attributed to $\mathrm{OH}$ stretching), 2921 and $2860 \mathrm{~cm}^{-1}$ (asymmetric and symmetric $\mathrm{CH}_{2}$ stretching), $1631 \mathrm{~cm}^{-1}$ (conjugated $\mathrm{C}=\mathrm{C}$ stretching), and $1097 \mathrm{~cm}^{-1}$ (C-O stretch in alcohols). The presence of these functional groups implies that the asreceived MWCNTs already have several functional groups that were introduced during the proprietary synthesis and/or purification processes. Thus, it could be possible that the hydroxy groups $(\mathrm{OH})$ of the AR CNTs may react with the hydrolyzed silane during the silanization process, without demanding a previous oxidation step. When the CNTs are oxidized, Figure $2 b$, similar infrared absorptions remain although there are changes in their relative intensity in addition to new peaks of small intensity at 1714$1726 \mathrm{~cm}^{-1}$, which may be assigned to stretching vibrations of carbonyl groups $(\mathrm{C}=\mathrm{O})$ due to carboxylic groups formed during the oxidation of hydroxyl compounds [29]. In addition to the presence of bands at $1726-1706 \mathrm{~cm}^{-1}$, Ox-CNTs show a relative increase in the intensity of the hydroxyl groups with respect to the intensity of the $\mathrm{CH}$ band $\left(3436 \mathrm{~cm}^{-1}\right)$ and $\mathrm{C}=\mathrm{C}\left(1631 \mathrm{~cm}^{-1}\right)$ bands. A specific experiment was also conducted to guarantee that the increased intensity of the hydroxyl groups in the oxidized CNTs is not due to absorbed water. For this experiment, as-received MWCNTs were exposed to the laboratory environment for several weeks and the analysis was repeated, finding no further increase in the $\mathrm{OH}$ signal.

The CNTs that were oxidized and then silanized, Figure 2c, show distinctive absorption bands at 1160 and $655 \mathrm{~cm}^{-1}$, characteristic of $\equiv \mathrm{Si}-\mathrm{O}-\mathrm{C} \equiv$ and $\mathrm{Si}-\mathrm{C}\left(\equiv \mathrm{Si}-\mathrm{CH}_{2}\right)$ functional groups, respectively. To better visualize these bands, a $600-1200 \mathrm{~cm}^{-1}$ window of the Ox-Sil CNTs is included in Figure 2d. In addition to the bands at 1160 and $655 \mathrm{~cm}^{-1}$ discussed above, a weak band at $817 \mathrm{~cm}^{-1}$ associated to $\mathrm{Si}-\mathrm{OH}$ is also appreciated in Figure $2 \mathrm{~d}$ as expected from the hydrolysis of the MPTMS. It is worth mentioning that the ratio of intensities $\mathrm{I}_{\mathrm{OH}} / \mathrm{I}_{\mathrm{CH}}$ in the Ox-Sil spectrum (Figure 2c) is lower than the corresponding $\mathrm{I}_{\mathrm{OH}} / \mathrm{I}_{\mathrm{CH}}$ ratio obtained from the spectrum of the Ox sample (Figure 2b). The reduction of $\mathrm{OH}$ groups because of the subsequent silanization treatment may be associated to reaction of some of these groups with the hydrolyzed silane. The above observations confirm the covalent attachment of silane molecules to the CNT surface for the 

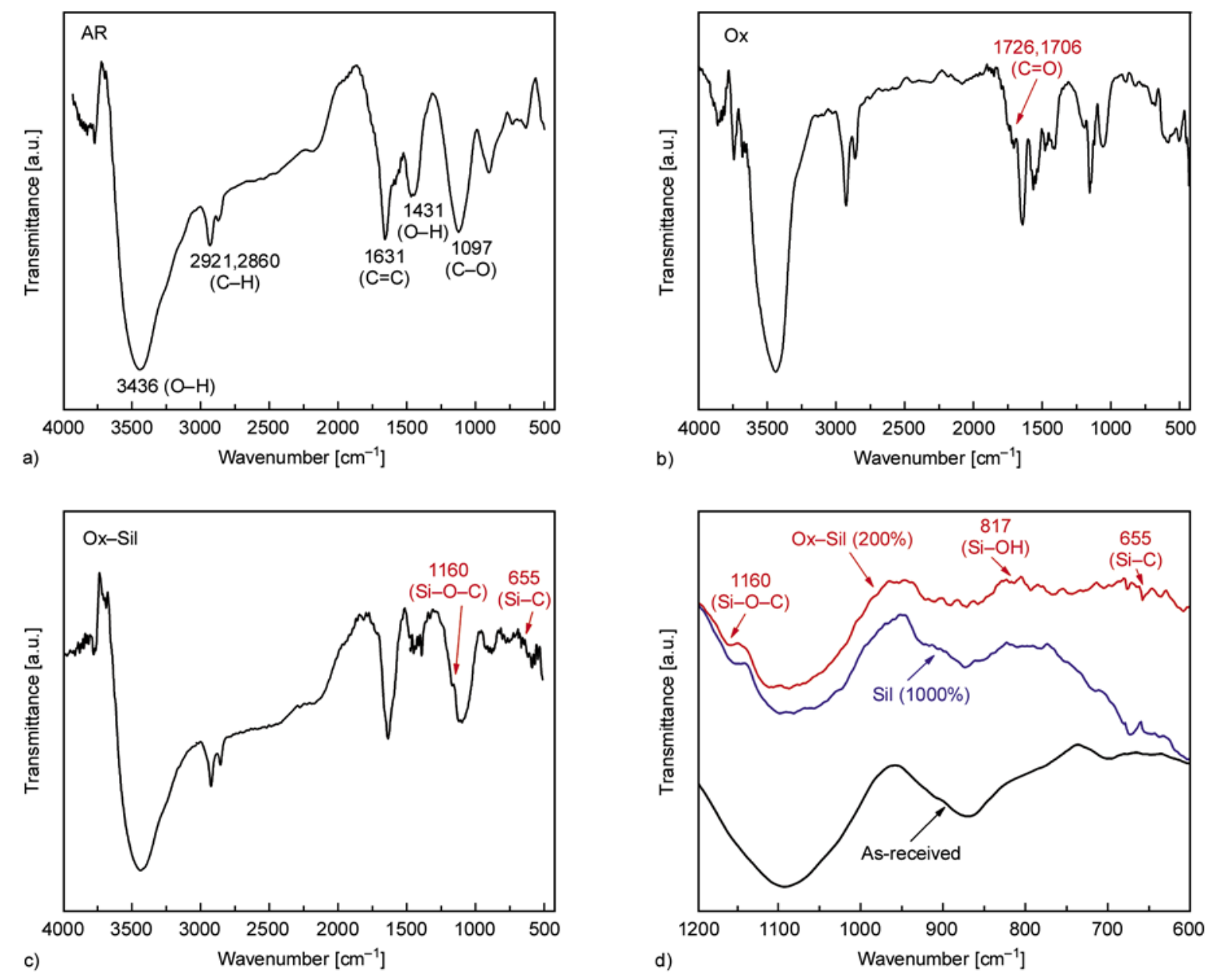

Figure 2. FT-IR spectra of MWCNTs. a) AR, b) Ox, c) Ox-Sil, d) 600-1200 $\mathrm{cm}^{-1}$ window of AR, Ox-Sil and Sil (1000 wt \%).

Ox-Sil treatment in agreement with the EDX results. One may expect that also both vinyl (unsaturations) and carbonyl groups from the methacrylate were present but due to their low absorptivity, low concentration, or overlapping with existing groups, they were not detected.

On the other hand, for the nanotubes that were directly silanized from the as-received material (Sil) the absorption bands at 1160,817 and $655 \mathrm{~cm}^{-1}$ (characteristic of attachment of silane molecules, see Figure 2c) were of very low intensity and hard to distinguish, which is related to the limited ability of the silane to bond to the non-oxidized CNT surface. Therefore, the IR spectrum of the original 'Sil' treatment (CNTs treated with $200 \mathrm{wt} \%$ of silane with respect to the weight of the CNTs) had no distinctive features and thus is not shown herein. Instead, Figure $2 \mathrm{~d}$ shows the spectrum of CNTs directly silanized from the as-received material using a more concentrated silane solution
$(1000 \mathrm{wt} \%)$. At this high silane concentration, some of the distinctive bands identified in the spectrum of the Ox-Sil treatment are visible but let obvious than for the Ox-Sil treatment. The excess of silane, however, may form layers of polysiloxanes on the CNT surface. Therefore, the FT-IR and EDX analyses conducted here suggest that, although several functional groups are already present in the as-received MWCNTs, these groups are not sufficient to promote adequate silane attachment to the surface of the CNT. According to these results, efficient chemical bonding between the MWCNTs and silane molecules demands a previous oxidative treatment.

An important issue to address when functionalizing CNTs is the possibility of CNT damage during the functionalization process. In our work, the oxidative process conducted by the nitric acid may yield CNT damage. Figure 3 shows TEM images of asreceived (AR), Figure 3a, oxidized (Ox), Figure 3b, and silanized MWCNTs that were previously oxi- 


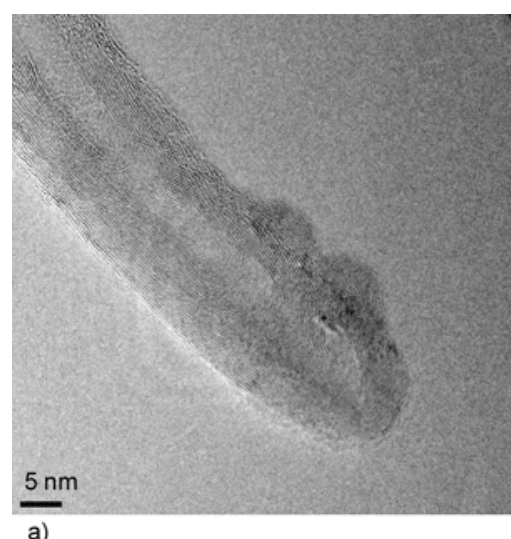

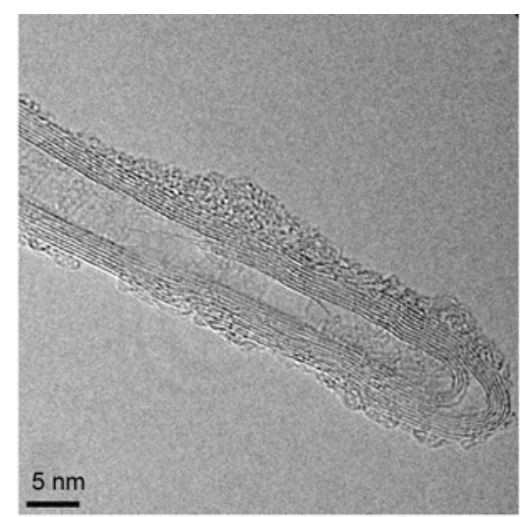

b)

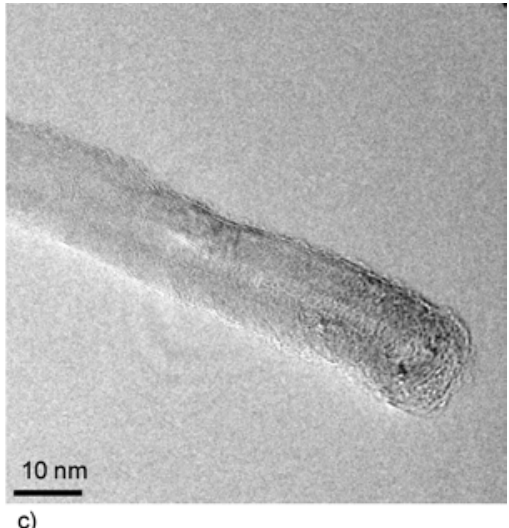

c)

Figure 3. TEM morphology of as-received and functionalized MWCNTs. a) AR, b) Ox, c) Ox-Sil.

dized (Ox-Sil), Figure 3c. As shown in Figure 3a, the AR nanotubes are mostly capped with inner and outer diameters varying between $3.2-6.6 \mathrm{~nm}$ and $11-25.5 \mathrm{~nm}$, in agreement with the information provided by the manufacturer [27]. The graphitic structure of the MWCNTs is composed of about 9-16 walls with an average separation between walls of $0.35 \mathrm{~nm}$. Some amorphous carbon is observed at the outermost layers of the AR MWCNTs, likely yielded by the synthesis and/or (proprietary) purification processes. When these CNTs are oxidized, the basic graphitic structure and tubular geometry are preserved but some of the graphitic layers are etched by the action of the nitric acid, Figure $3 \mathrm{~b}$. The etching action of the oxidative treatment also caused stripping of some nanotube walls, with the consequent thinning of the nanotubes. The subsequent silanization process, Figure 3c, does not show evidence of further CNT damage beyond that produced by the oxidative treatment. Notice that a capopen MWCNT is observed in Figure 3c. The defect generation and cap opening yielded by the oxidative process (although detrimental for the mechanical properties of the CNTs) should also yield more density of functional groups at those locations, and thus should favor the chemical reaction with the silane molecules and matrix bonding at these locations $[5,15,18]$.

\subsection{Mechanical characterization of nanocomposites}

Nanocomposites consisting of vinyl ester resin (VER) and MWCNTs employing one of the treatments listed in Table 1 were tested in axial compression. The stress $(\sigma)$-strain $(\varepsilon)$ compressive response of representative specimens is plotted in

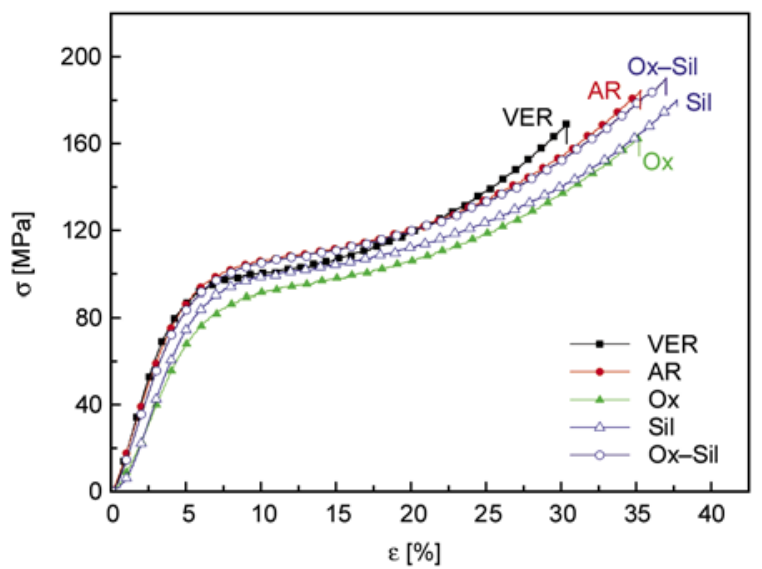

Figure 4. Compressive stress $(\sigma)$-strain $(\varepsilon)$ curves representative of the MWCNT/VER nanocomposites examined

Figure 4 . The representative specimens were chosen according to their similarity with the average measured properties, listed in Table 3 . The neat vinyl ester resin specimens were labeled 'VER', and the rest of the nomenclature employed for the composites follows that assigned to the CNT treatments listed in Table 1. For all specimens examined, an initial linear behavior is observed up to $\varepsilon \sim 4 \%$, where the onset of matrix yielding marks the initiation of nonlinear behavior, which continues up to specimen fracture. The nonlinear behavior observed is typical of thermosetting polymers under compression, which are normally highly linear and brittle in tension. To estimate the yield stress $\left(\sigma_{\mathrm{y}}\right)$, a $2 \%$ strain offset criteria was employed, calculating $\sigma_{\mathrm{y}}$ at the intersection of the $2 \%$ offset line with the $\sigma-\varepsilon$ curve. The average and standard deviation values of strength $\left(\sigma_{\max }\right)$, yield stress, compressive elastic modulus $(E)$, and ultimate strain $\left(\varepsilon_{\mathrm{ult}}\right)$, are listed in Table 3. Although overlapping of standard deviation (see Table 3) may compromise the strict 
Table 3. Average and standard deviation compressive properties of MWCNT/VER nanocomposites

\begin{tabular}{|l|c|c|c|c|}
\hline Material & $\boldsymbol{\sigma}_{\max }[\mathbf{M P a}]$ & $\boldsymbol{\sigma}_{\mathbf{y}}[\mathbf{M P a}]$ & $\mathbf{E}[\mathbf{G P a}]$ & $\boldsymbol{\varepsilon}_{\text {ult }}[\mathbf{M P a}]$ \\
\hline VER & $167.5 \pm 15.4$ & $91.3 \pm 6.51$ & $2.65 \pm 0.18$ & $30.6 \pm 1.33$ \\
\hline AR & $183.3 \pm 11.2$ & $97.6 \pm 1.63$ & $2.53 \pm 0.11$ & $35.3 \pm 2.02$ \\
\hline Ox & $163.2 \pm 8.82$ & $86.6 \pm 2.25$ & $2.34 \pm 0.09$ & $33.9 \pm 1.83$ \\
\hline Sil & $183.9 \pm 14.2$ & $96.9 \pm 5.75$ & $2.51 \pm 0.19$ & $36.6 \pm 1.79$ \\
\hline Ox-Sil & $186.4 \pm 11.6$ & $98.8 \pm 3.48$ & $2.54 \pm 0.10$ & $36.7 \pm 1.18$ \\
\hline
\end{tabular}

statistical significance of the results, trends between the different treatments can be clearly observed. As observed from Figure 4 and Table 3, the composites containing MWCNTs that were only oxidized (Ox) showed lower properties than the rest of the composites. This may be attributed to the CNT damage generated during the oxidative process, see Fig. $3 b$. These flaws on the MWCNTs may serve as defect initiation sites and trigger CNT fragmentation during the process employed to fabricate the composite, reducing the effective MWCNT length in the final composite. This will be further examined in connection with SEM images of the composite fracture surfaces. Another distinctive trend in the compressive response of the composites is the improved mechanical properties obtained for the Ox-Sil composites. The improvements, however, are limited, and the reasons for these marginal improvements may be due to a competition of factors. On the one hand, the adequate bonding of the silane molecules to the CNT surface suggested for the Ox-Sil treatment (see section 3.1.) should promote stronger CNT-to-polymer interfacial bonding and hence improved mechanical properties of the composite. On the other hand, the pre-requisite of oxidation for the Ox-Sil treatment may lead to defective/shorter CNTs in the composite. These competing factors may lead to limited improvements in the mechanical properties of the composites.

Lastly, it is observed that the average mechanical properties of the composites containing CNTs that were silanized without previous oxidation (Sil) are slightly lower than those of the Ox-Sil composites. Although the difference is minor, the trend is again consistent with the FT-IR and EDX results presented in the previous section, which suggest poor bonding of the silane molecules to the CNTs for the Sil treatment.

To gain further insight into the mechanical response of the composites, fracture surfaces of the tested composites were investigated. Figure 5 shows SEM observations of the fracture surfaces of the examined composites. MWCNTs are observed as bright spaghetti-like cylinders (or 'dots') immersed in the (dark) polymer matrix. Overall, the dispersion of the nanotubes within the matrix is moderate with some agglomerates still visible. Agglomeration is more obvious in the non-treated samples, Figure 5a. To further improve dispersion would demand more energy input during the dispersion process but such high energy processes may also promote CNT damage and length shortening [10, 14, 31]. Figure 5a shows some AR nanotubes pulled out and lying longitudinally over the vinyl ester matrix. Pulling out of the AR CNTs is somewhat expected since they are not functionalized to promote bonding with the polymeric matrix. At this scale, it is difficult to assess a difference in the density of pull-outs observed in the Ox composites, Figure 5b, with respect to the AR ones, Figure 5a. However, a distinctive feature is observed for the composites fabricated with the Ox-Sil nanotubes, Figure 5d, which shows a higher density of bright dots which is indicative of broken CNTs (instead of being pulledout). This finding suggests better interfacial bonding for the Ox-Sil composites, in agreement with the compression and FT-IR/EDX results discussed above.

An additional feature observed in all fracture surfaces of Figure 5 is the shorter length of the nanotubes with respect to its original length distribution. A detail transmission analysis of the as-received MWCNTs [32] yielded a length distribution of 1-4 $\mu \mathrm{m}$. After composite processing (Figure 5), although an accurate length distribution is very difficult to assess, it is clear that the great majority of the CNTs are shorter than $1 \mu \mathrm{m}$. For the mild chemical treatments employed here, certain CNT damage may occur during the initial oxidative process [33], but the silanization process is not expect to yield severe structural damage or length shortening of the CNTs. However, in our case, even the composites manufactured with non-treated MWCNTs show significant length shortening, see Figure 5a. Fu et al. [10] recently pointed out that the brittleness of CNTs may cause significant reduction of the CNT length during processing of the composite, and such a length reduction can severely detriment the mechanical properties of the composite. Although existent theoretical models $[9,34,35]$ present slight 


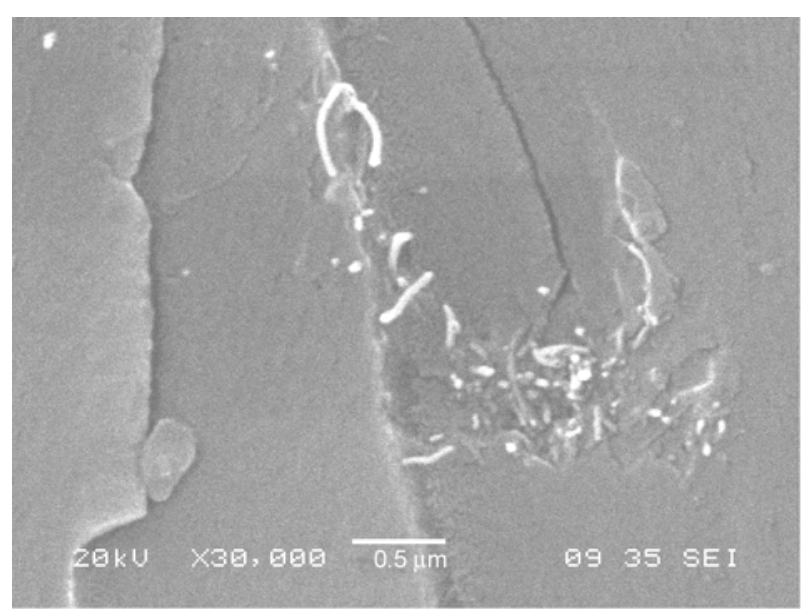

a)

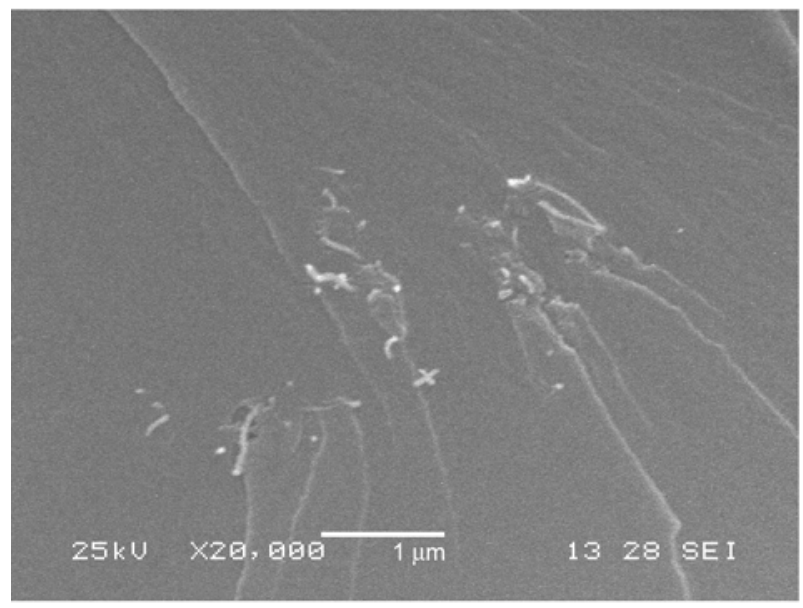

c)

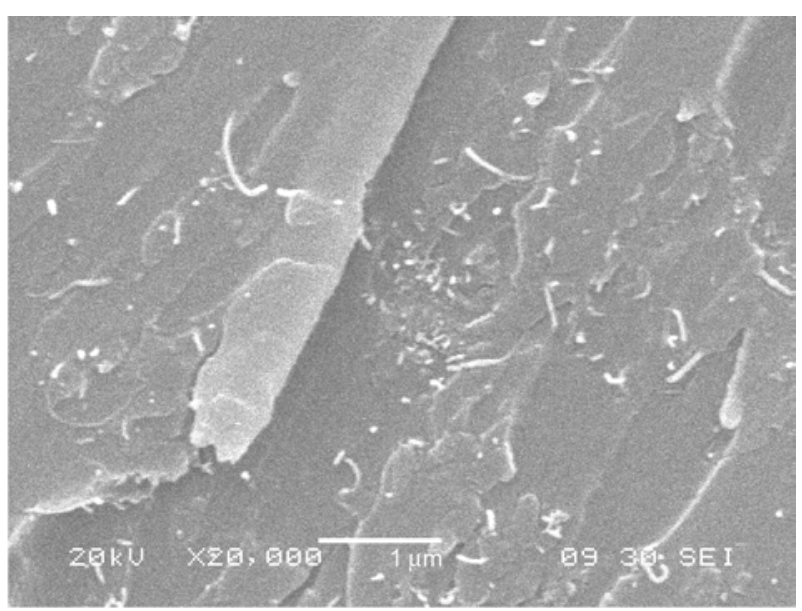

b)

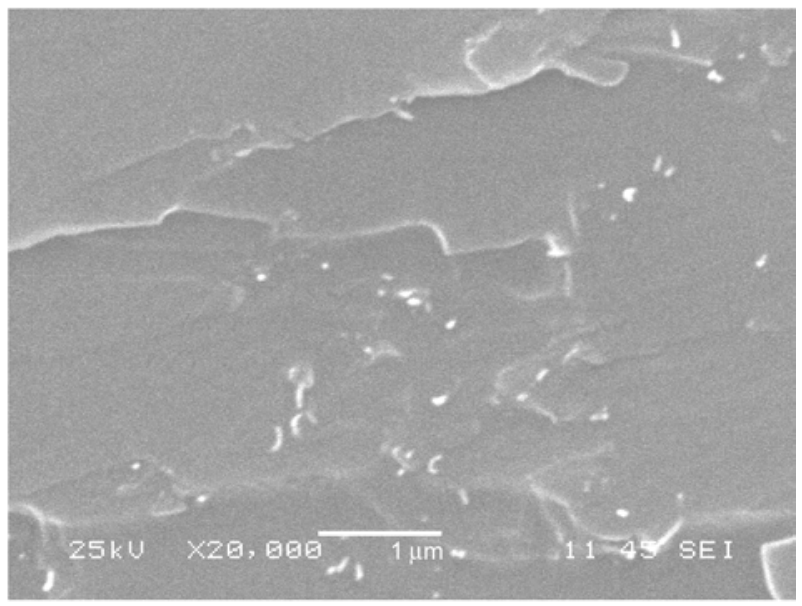

d)

Figure 5. Fracture surface of MWCNT/VER nanocomposites examined by SEM. a) AR, b) Ox, c) Sil, d) Ox-Sil.

variations in the predicted critical aspect ratio (length/diameter) of the CNTs, the consensus (at least from the modeling input) seems to be that an aspect ratio of at least 100 is needed for adequate load transfer between the CNT and polymer matrix. In our case, considering a length distribution of $1-4 \mu \mathrm{m}$ and a mean external diameter of $13 \mathrm{~nm}$ yields an aspect ratio of the pristine CNTs of 77308 , which is just above the critical aspect ratio allowed for adequate load transfer. Any shortening of the nanotubes, as evidenced by Figure 5, would greatly hamper the mechanical reinforcement effect of the CNTs in the polymer matrix.

\section{Conclusions}

Functionalization of multiwalled carbon nanotubes by acid oxidation and silanization was conducted. Two routes for MWCNT silanization were explored, a direct silanization of the as-received nanotubes without any previous treatment, and a method which involves oxidation and then silanization of the as-received CNTs. Even when the as-received CNTs have several functional groups originated during the synthesis (or purification), FT-IR and EDX analyses suggest better attachment of the silane molecules to the CNT when the nanotubes are previously oxidized. The better attachment of silane molecules to the CNTs for the sequential oxidation-silanization treatment correlates well with the improved compression properties of functionalized MWCNT/vinyl ester composites. Detailed TEM observations show evidence of slight CNT damage when the nanotubes are oxidized. When processing the composite, the initial CNT damage generated during functionalization is increased, causing CNT length shortening which limits the enhancement of the mechanical properties of the composite. 


\section{Acknowledgements}

This work was supported by CONACyT (Mexico) Grant No. 79609, directed by Dr. Avilés. Technical assistance of Rossana Vargas (CICY) with SEM and FT-IR analysis is strongly appreciated. TEM analysis by Dr. Arturo Ponce and Gerardo Martínez at CIQA is also acknowledged.

\section{References}

[1] Thostenson E. T., Ren Z., Chou T-W.: Advances in the science and technology of carbon nanotubes and their composites: A review. Composites Science and Technology, 61, 1899-1912 (2001).

DOI: $10.1016 / \mathrm{S} 0266-3538(01) 00094-\mathrm{X}$

[2] Thostenson E. T., Li C., Chou T-W.: Nanocomposites in context. Composites Science and Technology, 65, 491-516 (2005).

DOI: $10.1016 /$ j.compscitech.2004.11.003

[3] Tjong S. C.: Carbon nanotubes - Attractive nanofillers for forming bio-, functional and structural polymer composites. Express Polymer Letters, 4, 516 (2010).

DOI: $10.3144 /$ expresspolymlett.2010.65

[4] Eitan A., Jiang K., Dukes D., Andrews R., Schadler L. S.: Surface modification of multiwalled carbon nanotubes: Toward the tailoring of the interface in polymer composites. Chemistry of Materials, 15, 31983201 (2003).

DOI: $10.1021 / \mathrm{cm} 020975 \mathrm{~d}$

[5] Gojny F. H., Nastalczyk J., Roslaniec Z., Schulte K.: Surface modified multi-walled carbon nanotubes in CNT/epoxy-composites. Chemical Physics Letters, 370, 820-824 (2003).

DOI: $10.1016 / \mathrm{S} 0009-2614(03) 00187-8$

[6] Lau K-T., Gu C., Hui D.: A critical review on nanotube and nanotube/nanoclay related polymer composite materials. Composites Part B: Engineering, 37, 425436 (2006).

DOI: 10.1016/j.compositesb.2006.02.020

[7] Fiedler B., Gojny F. H., Wichman H. G. M., Nolte M. C. M., Schulte K.: Fundamental aspects of nano-reinforced composites. Composites Science and Technology, 66, 3115-3125 (2006).

DOI: $10.1016 /$ j.compscitech.2005.01.014

[8] Xie X-L., Mai Y-W., Zhou X-P.: Dispersion and alignment of carbon nanotubes in polymer matrix: A review. Materials Science and Engineering R: Reports, 49, 89112 (2005).

DOI: $10.1016 /$ j.mser.2005.04.002

[9] Duncan R. K., Chen X. G., Bult J. B., Brinson L. C., Schadler L. S.: Measurement of the critical aspect ratio and interfacial shear strength in MWNT/polymer composites. Composites Science and Technology, 70, 599605 (2010).

DOI: $10.1016 /$ j.compscitech.2009.12.010
[10] Fu S-Y., Chen Z-K., Hong S., Han C. C.: The reduction of carbon nanotube (CNT) length during the manufacture of $\mathrm{CNT} /$ polymer composites and a method to simultaneously determine the resulting CNT and interfacial strengths. Carbon, 47, 3192-3200 (2009). DOI: $10.1016 /$ j.carbon.2009.07.028

[11] Gryshchuk O., Karger-Kocsis J., Thomann R., Kónya Z., Kiricsi I.: Multiwall carbon nanotube modified vinylester and vinylester - based hybrid resins. Composites Part A: Applied Science and Manufacturing, 37, 1252-1259 (2006).

DOI: 10.1016/j.compositesa.2005.09.003

[12] Gao Y., Wang Y., Shi J., Bai H., Song B.: Functionalized multi-walled carbon nanotubes improve nonisothermal crystallization of poly(ethylene terephthalate). Polymer Testing, 27, 179-188 (2008). DOI: $10.1016 /$ j.polymertesting.2007.09.012

[13] Shen J., Huang W., Wu L., Hu Y., Ye M.: Thermophysical properties of epoxy nanocomposites reinforced with amino-functionalized multi-walled carbon nanotubes. Composites Part A: Applied Science and Manufacturing, 38, 1331-1336 (2007).

DOI: $10.1016 /$ j.compositesa.2006.10.012

[14] Chen H., Jacobs O., Wu W., Rüdiger G., Schädel B.: Effect of dispersion method on tribological properties of carbon nanotube reinforced epoxy resin composites. Polymer Testing, 26, 351-360 (2007).

DOI: $10.1016 /$ j.polymertesting.2006.11.004

[15] Tasis D., Tagmatarchis N., Bianco A., Prato M.: Chemistry of carbon nanotubes. Chemical Reviews, 106, 1105-1136 (2006).

DOI: $10.1021 / \mathrm{cr} 050569 \mathrm{o}$

[16] Xing Y., Li L., Chusuei C. C., Hull R. V.: Sonochemical oxidation of multiwalled carbon nanotubes. Langmuir, 21, 4185-4190 (2005).

DOI: $10.1021 / 1 \mathrm{a} 047268 \mathrm{e}$

[17] Zhu J., Kim J. D., Peng H., Margrave J. L., Khabashesku V. N., Barrera E. V.: Improving the dispersion and integration of single-walled carbon nanotubes in epoxy composites through functionalization. Nano Letters, 3, 1107-1113 (2003).

DOI: $10.1021 / \mathrm{n} 10342489$

[18] Datsyuk V., Kalyva M., Papagelis K., Parthenios J., Tasis D., Siokou A., Kallitsis I., Galiotis C.: Chemical oxidation of multiwalled carbon nanotubes. Carbon, 46, 833-840 (2008).

DOI: $10.1016 /$ j.carbon.2008.02.012

[19] Gojny F. H., Schulte K.: Functionalisation effect on the thermo-mechanical behaviour of multi-wall carbon nanotube/epoxy-composites. Composites Science and Technology, 64, 2303-2308 (2004). DOI: $10.1016 /$ j.compscitech.2004.01.024

[20] Seyhan A. T., Tanoglu M., Schulte K.: Tensile mechanical behavior and fracture toughness of MWCNT and DWCNT modified vinyl-ester/polyester hybrid nanocomposites produced by 3-roll milling. Materials Science and Engineering: A, 523, 85-92 (2009).

DOI: $10.1016 /$ j.msea.2009.05.035 
[21] Velasco-Santos C., Martínez-Hernández A. L., LozadaCassou M., Alvares Castillo A., Castaño V. M.: Chemical functionalization of carbon nanotubes through an organosilane. Nanotechnology, 13, 495-498 (2002). DOI: 10.1088/0957-4484/13/4/311

[22] Ma P. C., Kim J-K., Tang B. Z.: Functionalization of carbon nanotubes using a silane coupling agent. Carbon, 44, 3232-3238 (2006).

DOI: $10.1016 /$ j.carbon.2006.06.032

[23] Kathi J., Rhee K. Y.: Surface modification of multiwalled carbon nanotubes using 3-aminopropyltriethoxysilane. Journal of Materials Science, 43, 33-37 (2008).

DOI: $10.1007 / \mathrm{s} 10853-007-2209-2$

[24] Kathi J., Rhee K-Y., Lee J. H.: Effect of chemical functionalization of multi-walled carbon nanotubes with 3-aminopropyltriethoxysilane on mechanical and morphological properties of epoxy nanocomposites. Composites Part A: Applied Science and Manufacturing, 40, 800-809 (2009).

DOI: $10.1016 /$ j.compositesa.2009.04.001

[25] Ma P. C., Kim J-K., Tang B. Z.: Effects of silane functionalization on the properties of carbon nanotube/ epoxy nanocomposites. Composites Science and Technology, 67, 2965-2972 (2007).

DOI: 10.1016/j.compscitech.2007.05.006

[26] Kim H-C., Kim S-K., Kim J. T., Rhee K-Y., Kathi J.: The effect of different treatment methods of multiwalled carbon nanotubes on thermal and flexural properties of their epoxy nanocomposites. Journal of Polymer Science Part B: Polymer Physics, 48, 1175-1184 (2010).

DOI: $10.1002 /$ polb.22007
[27] Bayer Material Science AG. Kaiser-Wilhelm-Allee 51368, Leverkusen, Germany. www.baytubes.com (2011).

[28] Ashland Performance Materials. 5200 Blazer Parkway, Dublin, Ohio, USA. www.derakane.com (2011).

[29] Avilés F., Cauich-Rodríguez J. V., Moo-Tah L., MayPat A., Vargas-Coronado R.: Evaluation of mild acid oxidation treatments for MWCNT functionalization. Carbon, 47, 2970-2975 (2009).

DOI: $10.1016 /$ j.carbon.2009.06.044

[30] ASTM D695: Standard test method for compressive properties of rigid plastics (2002).

[31] Lu K. L., Lago R. M., Chen Y. K., Green M. L. H., Harris P. J. F., Tsang S. C.: Mechanical damage of carbon nanotubes by ultrasound. Carbon, 34, 814-816 (1996).

DOI: 10.1016/0008-6223(96)89470-X

[32] Avilés F., Ponce A., Cauich-Rodriguez J. V., Martínez G. T.: TEM observations of MWCNTs oxidized by mild experimental conditions. Fullerenes, Nanotubes and Carbon Nanostructures, in press (2011).

[33] Hong C-E., Lee J-H., Kalappa P., Advani S. G.: Effects of oxidative conditions on properties of multi-walled carbon nanotubes in polymer nanocomposites. Composites Science and Technology, 67, 1027-1034 (2007). DOI: $10.1016 /$ j.compscitech.2006.06.003

[34] Haque A., Ramassety A.: Theoretical study of stress transfer in carbon nanotube reinforced polymer matrix composite. Composite Structures, 71, 68-77 (2005). DOI: $10.1016 /$ j.compstruct.2004.09.029

[35] Wan H., Delale F., Shen L.: Effect of CNT length and CNT-matrix interphase in carbon nanotube (CNT) reinforced composites. Mechanics Research Communications, 32, 481-489 (2005). DOI: 10.1016/j.mechrescom.2004.10.011 